These results, establishing as they do the fact that methane and ethane are soluble in fuming sulphuric acid, are not without importance in their bearing toward gas analysis. A number of experiments were tried to determine the amount of absorption of each gas that took place in short intervals of time. After twenty-five per cent. of the methane obtained from natural gas had been absorbed, the residue was tested by measuring its absorption each hour. The results showed this absorption to be very slight, less than one-tenth cc. per hour. In the case of ethane, however, after over sixty per cent. had been absorbed, a similar series of experiments gave an average hourly absorption of $0.25 \mathrm{cc}$. equivalent to 0.60 per cent. of the ethane present.

In ordinary technical gas analysis, therefore, when the gas contains methane but no ethane, the absorption in the fuming sulphuric acid could be allowed to continue for an hour if necessary without much danger of serious error. But if ethane is present, fifteen minutes is the probable maximum of safety, and in any case the safest course to follow, especially in the case of an unknown gas, would be to shorten the time of contact with fuming sulphuric acid to the lowest possible limit.

IAFAYETTE, IND., October, IBgs.

[COXTRIBUTIONS FROM THE CHEMICAI LABORATORIES OF THE MASSACHUSETTS IXSTITUTE OF THCHNOROGY.]

\title{
THE VELOCITY OF THE REACTION BETWEEN SILVER ACETATE AND SODIUM FORMATE. A REAC- TION OF THE THIRD ORDER. ${ }^{1}$
}

\author{
By ARthUR A. Noyes AND George 'T. COTTLE. \\ Recetred Octoter 28, 2898 . \\ I. OBJECT OF THE INVESTIGATION.
} $\mathrm{HE}$ investigations hitherto made of the velocities of those
reactions in which two or more molecules of a substance enter have not yielded results of a general character. In many cases the velocity has been found proportional simply to the concentration of the substance, while in others it has been found proportional to that power of its concentration which corresponds to the number of its molecules entering into the reaction, as theoretical considerations would appear to demand. Thus, for ex-

1 Read before the Boston meeting of the American Chemical Society, August 25, 1898 . 
ample, the reactions between iron salts and potassium chlorate, ${ }^{1}$ between hydrogen peroxide and potassium iodide ${ }^{2}$, and between potassium bromate and potassium iodide ${ }^{2}$, in the presence of an excess of acid, are all simple reactions of the second order, although three or more molecules take part in the chemical change. In two cases, on the other hand, have the number of reacting molecules shown their influence; namely, that of the polymerization of cyanic acid, ${ }^{3}$ and that of the reaction between stannous chloride and ferric chloride, ${ }^{4}$ both of which, in correspondence with the number of reacting molecules, follow the law of the third order.

Further investigations of such reactions are therefore necessary. A new, and, it would seem, a suitable, example is the reaction between silver acetate and sodium formate, and we have, therefore, measured its velocity. The reaction is expressed by the following equation :

$2 \mathrm{AgC}_{2} \mathrm{H}_{8} \mathrm{O}_{2}+\mathrm{HCO}_{2} \mathrm{Na}=2 \mathrm{Ag}+\mathrm{CO}_{2}+\mathrm{HC}_{2} \mathrm{H}_{3} \mathrm{O}_{2}+\mathrm{NaC}_{2} \mathrm{H}_{3} \mathrm{O}_{2}$ or, more correctly, according to the dissociation theory :

$$
2+\overrightarrow{\mathrm{Ag}}+\mathrm{H}_{\overline{\mathrm{CO}}}=2 \mathrm{Ag}+\mathrm{CO}_{2}+\overline{\mathrm{H}} \text {. }
$$

Thus it is a simple trimolecular reaction and should apparently follow the law of the third order, if any such reaction does so. We have selected a salt of formic acid in place of the acid itself and a silver salt of a very weak acid, in order to eliminate as far as possible the catalytic effect of the hydrogen ions.

\section{DESCRIPTION OF THE EXPERIMENTS.}

The sodium formate and the silver acetate used were prepared by recrystallizing the commercial salts, their purity being assured by qualitative tests. An exactly normal solution of the first, and a nineteenth normal of the second were made. The strength of the former solution was determined by addition of hydrochloric acid to a known amount in a platinum dish, evaporating to dryness, and weighing the residue; that of the latter by titration with potassium thiocyanate.

1 Hood : Phit. Mag., (5), 6, 371; 8, 12I; 20, 323 ; Noyes and Wason : Ztschr.phys. Chem., 22, 210 .

2 Noyes and Scott : Ztschr. phys. Chem, , 18, r18.

8 Van't Hoff : Fttudes de Dynamique Chimique, S. go.

4 Noyes: Ztschr. phys. Chem, , I6, 546. 
As the velocity of the reaction is very small at ordinary temperatures, we carried on the experiments at $100^{\circ}$. For this purpose we constructed a steam thermostat out of a cylindrical tin can. In the cover, before it was soldered on, were cut one small hole, for a ball condenser, and five large holes, two inches in diameter, provided with quarter-inch tin collars covered with rubber tubing. In these were then placed large $225 \mathrm{cc}$. testtubes containing the measured amounts of silver acetate solution and of water. In the cases where the concentration of the silver solution was 0.100 normal, solid silver acetate was weighed directly into the tube and the necessary amount of water added, as so strong a solution of the sait cannct be prepared in the cold. Each of the large tubes was then fitted with a cork through which were passed a small twenty-firecc. test-tube containing the required amount of formate solution and of water, a thermometer, an efficient glass stirrer, and tubes for blowing out samples. The water in the bottom of the thermostat was kept boiling constantly, and when the temperature of the solution had become quite constant, the bottom of the small tube was broken by a glass rod, the two solutions immediately mixed by violent stirring, and the time (to the second) noted. At definite moments samples of the mixture were blown out into measured amounts of ice-cold standardized potassium thiocyanate solution, thus instantly stopping the reaction. As the flasks containing the thiocyanate were weighed before and after addition of the sample, the amount of the latter was easily determined. The end-point was then determined after filtration by titration with silver nitrate and potassium thiocyanate solutions, using ferric alum as an indicator. Thus the silver content of the mixture and the progress of the reaction were ascertained.

III. EXPERIMENTAL RESULTS AND VELOCITY CONSTANTS.

The results of the experiments and the calculated velocityconstants are found in the following tables. All experiments were carried out at the temperature of water boiling under atmospheric pressure. $A$ expresses the original concentration of the sodium formate, and $B$ that of the acetate. Under $t$ are found the time in minutes reckoned from the moment of mixing. Under $(B-x)_{1}$ and $(B-x)_{2}$ are given the concentrations of the silver 
acetate found in two separate experiments after the time $t$, and under $B-x$ will be found the average of these results. Under $C_{2}$ and $C_{3}$ are given the constants of the second and of the third order respectively which occur in the equations :

$$
\begin{aligned}
& \frac{d x}{d t}=C_{2}(A-x)(B-x) \text { and } \\
& \frac{d x}{d t}=C_{3}(A-x)(B-x)^{2} .
\end{aligned}
$$

They are calculated, of course, from the corresponding integrated equations. ${ }^{1}$ At the foot of each column of the $C_{2}$ values, is given the value, obtained by interpolation, corresponding to the time when the reaction is one-half completed. Under each column of $C_{3}$ values, the mean of the same is given.

FIRST Sekies.

$\begin{array}{cccc}A=0.100 ; & B=0.100 . & & \\ (B-x)_{2} . & B-x . & C_{2} . & C_{3} . \\ \cdots \cdots \cdots & 0.06694 & 2.57 & 30.8 \\ \cdots \cdots & 0.05334 & 2.19 & 31.3 \\ \cdots \cdots & 0.04684 & 1.89 & 29.6 \\ \cdots \cdots & 0.03784 & 1.83 & 33.3 \\ \cdots \cdots & 0.03235 & \underline{1.61} & \underline{30.6} \\ & & \underline{2.05} & 3 \mathrm{II} .1\end{array}$

SECOND SERIES.

$$
A=0.100 ; B=0.050 \text {. }
$$

$\begin{array}{rlllll}2 & 0.03774 & 0.03776 & 0.03775 & \text { I.5I } & 34.9 \\ 4 & 0.03090 & 0.03080 & 0.03085 & \text { I.35 } & 35.1 \\ 7 & 0.02455 & 0.02425 & 0.02440 & \text { I.20 } & 35.9 \\ \text { II } & 0.01959 & 0.01958 & 0.01959 & \text { I.04 } & 35.6 \\ \text { I7 } & 0.01519 & 0.01483 & 0.0150 \mathrm{I} & \frac{0.91}{16} & \frac{36.7}{35.6}\end{array}$

Third Shries.

$$
A=0.050 ; B=0.100 \text {. }
$$

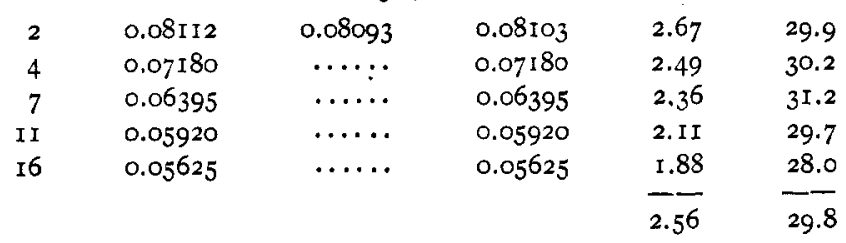

1 Cf. Fuhrmann: Ztschr. phys. Chem., $4,89$. 
ARTHUR A. NOYES AND GEORGE T. COTTLE.

FOURTH SERIES.

$A=0.050 ; B=0.050$.

$\begin{array}{rccccc}t . & (\mathrm{B}-x)_{1} . & (\mathrm{B}--x)_{2} . & \mathrm{B}-x . & C_{2} . & C_{3} . \\ 3 & 0.04019 & 0.04047 & 0.04033 & 1.60 & 35.8 \\ 8 & 0.03145 & 0.03173 & 0.03159 & 1.46 & 37.6 \\ 16 & 0.02473 & 0.02463 & 0.02468 & 1.28 & 38.8 \\ 25 & 0.02033 & 0.02066 & 0.02048 & \mathrm{I} .16 & 37.6 \\ 45 & 0.01629 & \ldots \ldots & 0.01629 & 0.92 & 37.4 \\ 80 & 0.01250 & \ldots \ldots . & 0.01250 & \underline{0.75} & \underline{37.5} \\ & & & & \underline{1.29} & 37.4\end{array}$

FIFTH SERIES.

$A=0.050 ; B=0.0250$.

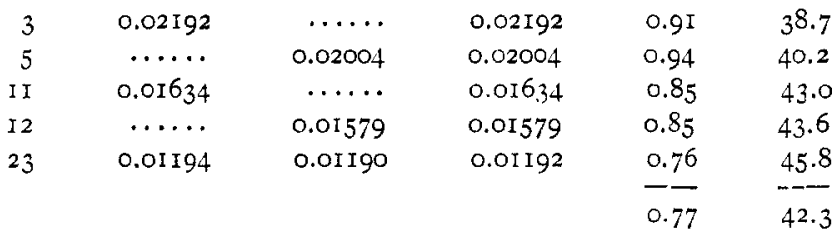

SIXTh SERIES.

$A=0.0250 ; B=0.050$.

$\begin{array}{llllll}\text { I0 } & 0.03766 & \ldots \ldots & 0.03766 & 1.49 & 37.3 \\ 25 & 0.03 \mathrm{I} 36 & \ldots \ldots & 0.03 \mathrm{I} 36 & 1.44 & 38.6 \\ 45 & 0.02840 & \ldots \ldots & 0.02840 & 1.27 & 37.3 \\ 80 & 0.02653 & \ldots \ldots & 0.02653 & 1.08 & \underline{34.4} \\ & & & & 1.49 & 36.4\end{array}$

Seventh Series.

$A=0.0250 ; B=0.0250$.

$\begin{array}{llllll}10 & 0.02024 & 0.02009 & 0.02017 & 0.96 & 42.9 \\ 25 & 0.01626 & 0.01623 & 0.01624 & 0.86 & 43.8 \\ 45 & 0.01297 & 0.01276 & 0.01286 & 0.84 & 49.3 \\ 80 & 0.01140 & 0.01120 & 0.01130 & 0.61 & \frac{39.0}{43.7}\end{array}$

IV. DISCUSSION OF THE RESULTS.

Let us now consider the significance of the experimental results. In order to ascertain the order of a reaction and the influence of the individual substances upon its velocity, there are, as is well known, two different methods. ${ }^{1}$ The first of these methods consists in determining the degree of the differential equation whose constants show the least variation during a sin-

1Cf. Noyes: Ztschr. phys. Chem., 18, II9; 22, 215. 
gle experimental series. A brief glance at the preceding tables suffices to show that, in every series, the values of $C_{2}$ exhibit a constant, and as a rule very considerable, diminution during the progress of the reaction. On the other hand, the tables also show that the values of $C_{\mathrm{s}}$ remain practically constant. The reaction, judged by this method, is therefore one of the third order.

The second method of determining the order of a reaction consists in degree of the equation whose constants retain nearly the same value in independent series of experiments with very different original concentrations. This method is much more reliable than the former, because the effect of disturbances, such for example as the influence of the products of the reaction upon the velocity, in comparison with the much greater effect of the large variations in the original concentration, becomes of no consequence. In order to show more distinctly the results obtained by the application of this second method to the reaction considered here, we present the following table, in which the comparable values of the constants of both orders derived from the seven experimental series are given. Under $C_{s}$ the mean values are shown, while under $C_{2}$ the values are given which correspond to the state of the reaction in which one-half of the substance present in smallest amount has undergone change.

\begin{tabular}{ccccc}
$\begin{array}{c}\text { Series. } \\
\text { No. }\end{array}$ & \multicolumn{2}{c}{ Normal concentration of } & & \\
I & 0.100 & 0.100 & $C_{2}$. & $C_{3}$. \\
2 & 0.100 & 0.050 & 2.05 & $3 I . I$ \\
3 & 0.050 & 0.100 & 1.22 & 35.6 \\
4 & 0.050 & 0.050 & 2.56 & 29.8 \\
5 & 0.050 & 0.025 & 1.29 & 37.4 \\
6 & 0.025 & 0.050 & 0.77 & 42.3 \\
7 & 0.025 & 0.025 & 1.49 & 36.9 \\
& & 0.67 & 43.7
\end{tabular}

It is evident that the values of $C_{\mathrm{s}}$ in all seven of the series are approximately the same, while those of $C_{2}$ vary about 280 per cent., which proves that the reaction is essentially one of the third order, and that its velocity is nearly proportional to the concentration of the sodium formate and to the square of the concentration of the silver acetate. In the case of this reaction, therefore, the two methods for the determination of the order of a reaction, lead to the same conclusion. 
Still, we must not leave unmentioned the fact that the proportionality between the velocity and the square of the concentration of the silver acetate is not absolutely exact. While the change of the original concentration of the formate exerts no definite influence upon the constants of the third order, yet, as will be seen from the last table, there occurs with every diminution of the original concentration of the silver salt, a slight, but still unmistakable, increase in the values of the constants $C_{3}$. As to the cause of this phenomenon, nothing can be said with certainty. It is not improbable, however, that the greater velocity in the more dilute solutions depends upon the greater dissociation of the silver salt, it being then assumed that only the silver ions are capable of reacting.

V. SUMMIARY.

By this research it is established that the reaction between sodium formate and silver acetate proceeds with a velocity which is proportional to the concentration of the former salt, and nearly proportional to the square of the concentration of the latter. As this reaction, according to prevailing molecular ideas, takes place between one molecule of the formate (or of its anion) and two molecules of silver acetate (or of its silver ion), its observed velocity is in accordance with the theoretical requirements, and it furnishes a new confirmation of the influence of the number of the molecules taking part in reactions.

\section{COUMARIN AND VANILLIN, THEIR SEPARATION, ESTIMATION AND IDENTIFICATION IN COM- MERCIAL FLAVORING EXTRACTS.'}

BY Willtam H. HESS AND ALBERT B. PRescott.

Received November $3_{7}, 1898$.

$T^{T}$ is a common practice in preparing an extract of vanilla from 1 vanilla beans, to introduce also, as a lower-priced material, a portion of tonka beans. This makes a cheaper article and one that is generally popular with consumers. It is understood, however, to be an inferior article when compared with the genuine, and it can no longer be correctly labeled "Vanilla Extract." Under this name the presence of tonka extract constitutes an adulteration and hence the separation, identification, and esti-

\footnotetext{
1 Read by title before the New York meeting of the American Chemical Society, December 28 , 1898 .
} 